\title{
Scientists go to jail to crack substance abuse
}

\section{Emily Singer, Washington}

The US National Institute on Drug Abuse (NIDA) is embarking on a programme to study the treatment of drug abuse among prisoners in the United States - and to educate judges about the neurobiology of addiction.

NIDA officials hope that the programme will help to break the cycle of drug abuse, crime and imprisonment by finding better ways of selecting prisoners for different drug treatment options. The institute plans to spend $\$ 30$ million on the programme over the next five years, conducting studies at ten prison sites across the country.

At a panel discussion at the Society for Neuroscience meeting in New Orleans last month, NIDA director Nora Volkow referred to the programme, which she dubbed "NIDA goes to jail", as an example of how scientists can interact with societal issues.

Drug abuse is a vast problem for the US criminal-justice system: $60 \%$ of inmates have been convicted of drug-related offences. Nine out of ten parolees with a history of drug abuse return to drugs, according to Douglas Marlowe, a psychologist and criminal-justice researcher at the University of

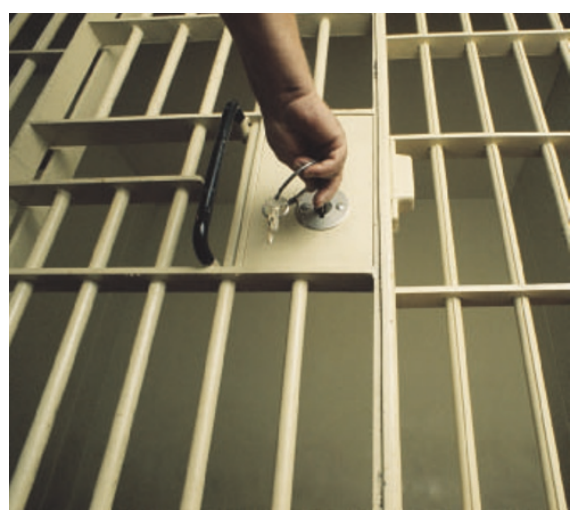

Behind bars: three out every five US prisoners were convicted of drug-related offences.

Pennsylvania in Philadelphia, and many are re-arrested on drug-related charges.

The programme is still at the planning stage, NIDA officials say, but is likely to begin with a survey of prison administrators, clinicians, wardens and parole officers at the ten sites to establish existing treatment patterns.

NIDA will also sponsor clinical trials, beginning next year, of different ways of assessing prisoners for treatment before their release. By measuring factors such as motivation for treatment and levels of hostility, anxiety and risk-taking behaviour, researchers hope to match patients with the best type of treatment, says Wilson Compton, a psychiatric epidemiologist and head of prevention research at NIDA. "People haven't focused adequately on this population," he says.

The institute also plans to step up its efforts to educate judges and police officers on the biology of addiction. Officials at Treatment Accountability for Safer Communities (National TASC), an organization based in Alexandria, Virginia, that helps to treat drug addicts, say that NIDA has been consulting with it on how best to do this. A National TASC report on current education efforts should be ready within a month, and will help NIDA to plan a pilot education programme to be conducted in North Carolina.

Marlowe thinks that this type of education is badly needed. "Judges have heard that drug addiction is a disease, but they don't know what that means," says Marlowe. "They don't understand why a person relapses after being drug-free in jail for six months. If they know how cravings are triggered by environmental cues, they would understand."

\section{Climate study highlights inadequacy of emissions cuts}

Quirin Schiermeier, Munich

As representatives from 188 countries gather in Milan, Italy, to work through the latest round of negotiations for the Kyoto Protocol on limiting greenhouse-gas emissions, German researchers have released a study showing that "intolerable" levels of climate change are more likely than decision-makers may realize.

In a report published on 25 November, the German Advisory Council on Global Change contends that the world can tolerate a rise of up to $2{ }^{\circ} \mathrm{C}$ over pre-industrial levels. Beyond this, the effects of climate change on society would become too severe, they say. This would be mainly due to sudden phenomena such as the possible irreversible disintegration of large ice sheets, or abrupt disturbances to the North Atlantic Ocean's currents and to monsoons in Asia.

Global mean temperatures have already increased by $0.6^{\circ} \mathrm{C}$ since 1900 . By the end of the twenty-first century, temperatures may increase by a further $1.4-5.8^{\circ} \mathrm{C}$, according to the latest projection of the Intergovernmental Panel on Climate Change.

Even the lower limit of this estimate will pose an intolerable threat to human health, food and water supplies, economic development and natural ecosystems in many parts of the world, says the German report.

But it seems unlikely that political action will be able to keep temperature increases down. The 1997 Kyoto Protocol has yet to be ratified, as Russia has not decided whether to sign it. But even if the protocol comes into effect, the cuts that it prescribes will be insufficient to hold climate change to a 'tolerable' level, the report says.

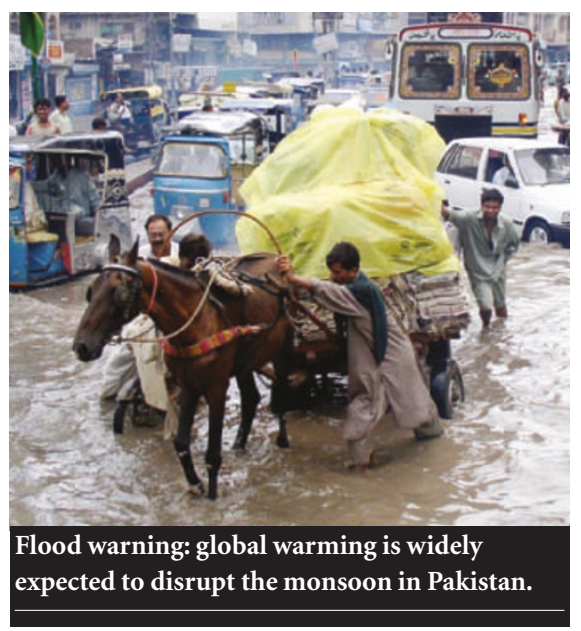

It concludes that global carbon dioxide emissions would need to be curbed by $45-60 \%$ by 2050 compared with 1990 levels to avoid dangerous climate change. The Kyoto Protocol calls for average cuts of 5\% in industrialized countries by 2012, and even that may be unrealistic.

The report will be presented in Milan at the ninth Conference of the Parties to the United Nations Framework Convention on Climate Change on 10 December. But it is unlikely to have an immediate impact on Kyoto negotiations, say the report's authors.

"These findings reinforce our position," says Karsten Sach, head of the German environment ministry's international climate-protection department, and leader of the German delegation in Milan. Germany is committed to a reduction of $40 \%$ in its emissions by 2020 , he says, regardless of whether the Kyoto Protocol comes into effect. Other European countries, including Britain, France, Sweden and the Netherlands, have similarly set their own goals.

Plans for a climate-protection strategy beyond Kyoto are not yet on the table, but some analysts expect the Italian host delegation in Milan to outline possible next steps. 